\title{
Credit and equity rationing in markets with adverse selection
}

\author{
Thomas Hellmann*, Joseph Stiglitz ${ }^{1}$
}

Graduate School of Business, Stanford University, Stanford, CA 94305-5015, USA

Received 1 January 1996; accepted 1 August 1998

\begin{abstract}
Previous theories of financial market rationing focussed on a single market, either the credit or the equity market. An interesting question is whether credit and equity rationing are mutually compatible, and how they interact. We consider a model with twodimensional asymmetric information, where entrepreneurs have private information about both the expected returns and the risk of their projects. We show that credit and equity rationing may occur individually or simultaneously. Moreover, competition between the two markets may generate the adverse selection that leads to rationing outcomes. (C) 2000 Elsevier Science B.V. All rights reserved.
\end{abstract}

JEL classification: G1

Keywords: Credit market; Equity market; Rationing equilibrium; Adverse selection

\section{Introduction}

In their 1981 paper, Stiglitz and Weiss showed that credit rationing could occur when investors have less information than the entrepreneurs about the

*Corresponding author. Tel.: 1650723 6815; fax: 1650725 9932; e-mail: hellmann@ leland.stanford.edu. Website: www.stanford.edu/ hellmann/

${ }^{1}$ Chief Economist and Senior Vice-president of the World Bank, Washington, D.C., and on leave from the Department of Economics, Standard University. 
risk of an investment. A literature developed on the basis of this simple model. Cho (1986) noted that adverse selection would disappear in the 1981 model if investors used equity instead of debt. Using a different set of assumptions - the most important difference being that expected returns and not risk was the parameter of asymmetric information - Myers and Majluf (1984) and Greenwald et al. (1984) showed that equity markets could have rationing too. This raised the issue of whether theories of credit and equity rationing could be made compatible. DeMeza and Webb (1987) integrated the various approaches and showed the following result: If there is asymmetric information about expected returns, then investors prefer debt over equity and there cannot be any credit rationing. But if there is asymmetric information about risk, then investors prefer equity over debt and there cannot be any equity rationing. At a first glance, this result seems to solve the issue: as long as investors use the appropriate financial instrument, there cannot be any rationing. The analysis of DeMeza and Webb, however, did not allow for asymmetric information about both expected returns and risk.

A number of other papers also questioned the rationing outcome. Bester (1985a), Milde and Riley (1988) and Grinblatt and Hwang (1989) introduced variable loan sizes to give investors a second instrument besides price to screen loan applicants. Wette (1983) and Bester (1985b) allowed investors to extract information from the entrepreneurs through the use of collateral requirements. ${ }^{2}$ The work of Leland and Pyle (1977), Stiglitz (1982) and Brennan and Kraus (1987) similarly suggested that co-investment requirement and capital structure could be used to screen applicants. This line of research showed how investors can solve the rationing problem by offering more complicated financial contracts. In the ensuing separating equilibrium investors offer a menu of contracts that induces self-selection among entrepreneurs in such a way that the equilibrium actually reveals the asymmetric information.

One issue with this approach is that the structure of optimal contracts is very sensitive to the specific nature of asymmetric information and the particular instruments available to investors. Contracts are chosen solely to induce selfselection and the asymmetric information is sufficiently small so that the optimal contracts can separate most or all types. In many real economic situations the environment may be too complex for investors to separate out all relevant information through the clever use of financial contracts.

Another limitation is that investors are all the same, all offering the same optimal menu of contracts. In reality investors are often heterogeneous and they specialize in particular forms of financing. Banks, for example, specialize in

\footnotetext{
${ }^{2}$ The work of Leland and Pyle (1977), Stiglitz and Weiss (1981) and then Stiglitz and Weiss (1986) also considered collateral requirements and showed that these may not always suffice to eliminate the rationing outcome.
} 
credit instruments while private equity funds specialize in equity. ${ }^{3}$ Entrepreneurs seek out these various types of investors and they choose their funding structure based on the offers investors make and based on their own preferences.

These observations lead us to believe that it may be interesting to model credit and equity markets as an environment where there are heterogeneous investors that are competing with each other to finance entrepreneurs that have a large amount of private information. The question we pursue in this paper is whether in such circumstances credit and equity markets always clear or whether there can be rationing. One of the reasons why little research has been done along those lines is that it is technically difficult to model such an environment. In this paper we hope to make a first step in this direction. In our model investors specialize in one of two standard financial contracts, debt or equity. There is asymmetric information about both the expected returns and the risk of the entrepreneurs' projects. To make the model tractable we use two strong simplifying assumptions. Investors can only set prices. And entrepreneurs can accept funding from either the debt or the equity market, but not from both.

Our main result is that in such a model there may indeed be credit rationing, equity rationing or even simultaneous credit and equity rationing. The most surprising part is that rationing may actually be the result of competition between these two sets of specialized investors.

We first establish that although investors specializing in debt attract better entrepreneurs (i.e., higher expected returns) they also attract riskier entrepreneurs (i.e., higher variance). Increasing the price of debt has three effects on the returns to debt. First, there is the usual positive price effect. Second, there is a positive selection effect of losing some low-return high-risk entrepreneurs. Third, there is an adverse selection effect of losing some high-return low-risk entrepreneurs who switch to the equity market. If the adverse selection effect dominates the two other effects, returns to debt decrease in their own price. Debt investors may be unwilling to raise their prices in the presence of excess demand, and rationing occurs. Similar reasoning applies to the equity market. As a consequence, market equilibrium may feature credit rationing, equity rationing or even both.

In the traditional model, adverse selection comes from the fact that, as prices increase, some of the best entrepreneurs no longer want to invest. As prices increase in this model, some of the best entrepreneurs switch to the other market. If there are many entrepreneurs switching between the two markets, investors may compete more fiercely by lowering their prices. Prices may fall below their Walrasian levels and rationing ensues. We also show that if all investors were to specialize in equity, the market would always clear. Together,

\footnotetext{
${ }^{3}$ Interestingly, even in countries where banks are allowed to hold equity they typically take equity only in rare circumstances and mostly in large public corporations.
} 
these results show that the existence of heterogeneous specialized investors can have an important impact on the equilibrium.

The structure of the paper is as follows. Section 2 develops the basic model. Section 3 explains the self-selection process. Section 4 examines the investors' return functions. Section 5 discusses the various rationing equilibria. It is followed by a brief conclusion.

\section{The basic model}

We consider a model with a continuum of entrepreneurs and investors. Entrepreneurs have an investment project that requires one unit of outside capital. They have limited liability, no collateral and their opportunity cost of working on the project is $K$. The project either fails and yields no returns, or it succeeds and yields verifiable returns $\pi$. The probability of success is $(1 / \sigma)$. We write $\pi=\sigma \mu$, so that the expected returns is $(1 / \sigma) \sigma \mu=\mu$, and $\sigma$ measures risk. $^{4}$ There is asymmetric information about both $\mu$ and $\sigma$. Investors do not know the entrepreneurs' types, denoted by $\theta \equiv(\mu, \sigma) \in[0, \infty) \times[1, \infty)$, but only the joint distribution $N(\theta)$, with density $n(\theta)$. There is no discounting, all parties are risk-neutral and there are no bankruptcy costs. ${ }^{5}$

As discussed in the introduction, there are two distinct types of investor. The first set of investors specializes in debt (or credit - we will use these two terms interchangeably). A debt contract specifies a fixed value of $D$ (interest plus principle) that an entrepreneur owes the investors. In case of success entrepreneurs receive $\max [0, \pi-D]$. The second set of investors specializes in equity. An equity contact specifies the investor's percentage share $E$. In case of success entrepreneurs receive $(1-E) \pi$.

Let $U$ and $V$ denote the expected returns of entrepreneurs and investors, then $U(D ; \theta)=(1 / \sigma)(\mu \sigma-D)=\mu-D / \sigma, U(E ; \theta)=(1-E) \mu, V(D ; \theta)=D / \sigma$ and $V(E ; \theta)=E \mu$. Entrepreneurs are willing to participate as long as their expected returns exceed their opportunity costs, i.e., $U(i, \theta) \geq K, i=D, E .^{6}$

Let $R_{D}$ and $R_{E}$ be the expected returns of debt and equity investors. In Section 3 we will examine how these depend on the self-selection of entrepreneurs. The supply of funds could depend on a number of factors, including taxes,

\footnotetext{
${ }^{4}$ In Hellmann and Stiglitz (1995) we also examine a more general specification where $\mu$ and $\sigma$ represent general parameters of first-order and second-order stochastic dominance.

${ }^{5}$ The assumption of risk-neutrality is not essential to our arguments (see Stiglitz and Weiss (1987) for a model with risk-aversion). Nothing substantial would change in the model with risk-aversion as long as Lemma 1 holds. Bankruptcy costs have an effect similar to risk-aversion when borne by the entrepreneurs. When borne by the investors, they may provide a separate rationale for credit rationing, as shown by Williamson (1987).

${ }^{6}$ Note that $\mu \geq K$ is a necessary condition for the participation constraint to be satisfied.
} 
risk-preferences, regulatory restrictions or the cost of specialization. We do not model this explicitly, but instead use a general specification for the supply functions. In particular, the supply of funds in a market can be any nondecreasing function of its return. We write $Q_{D}\left(R_{D}\right)$ and $Q_{E}\left(R_{E}\right) .^{7}$

The literature on financial market rationing has been using a price-setting equilibrium concept. Market prices are not determined simply by the equality of supply and demand (the 'Walrasian' outcome). Instead, for a given quantity of funds in the market, prices maximize investors' returns. And the quantity of funds is such that the marginal investor makes zero profits. Finally, individual investors are small, so that they take the environment as given.

To use this equilibrium concept in our model, we assume the following time line. Debt and equity investors commit funds $Q_{D}$ and $Q_{E}$ to invest in a given class of (observationally identical) entrepreneurs. They then announce prices $D$ and $E$ at which those funds are available. Entrepreneurs can seek out all of these funds, but they can accept at most one offer. ${ }^{8}$ If they receive funds they invest in their project. If the project succeeds, the returns will be divided according to the debt or equity contact.

An equilibrium of this game must satisfy three conditions. First, given the prices and quantities offered in the market, entrepreneurs self-select to maximize their expected utility. Second, given the quantities of funds committed to the debt and equity market, investors must be offering prices that maximize their expected returns. Third, given the expected return in both markets, investors are supplying their desired quantity of funds.

Our model and equilibrium concept rests on a number of important assumptions. Investors are the uninformed party and they move first. Stiglitz and Weiss (1990) explain that this generates screening rather than signaling behavior. Screening equilibria are more likely to have pooling outcomes where the market does not reveal all information in equilibrium. Entrepreneurs in this model can apply to all contracts. This eliminates the possibility that investors can induce self-selection through the rationing probabilities. Entrepreneur also cannot combine debt and equity, and investors have price as their only instrument. These assumptions were chosen so that investors cannot separate out the entrepreneurs' types through the clever use of a menu of contracts. We use this model specification because we want to model an environment that is complex relative to the instruments available to investors. Given the difficulty of modeling truly complex environments, we use some simplifying assumptions on the instruments available to investors to maintain a desired

\footnotetext{
${ }^{7}$ The model can also be trivially extended to allow for cross-returns effects, i.e. $Q_{D}\left(R_{D}, R_{E}\right)$ and $Q_{E}\left(R_{D}, R_{E}\right)$.

${ }^{8}$ The easiest way to imagine the market process is that entrepreneurs arrive serially in random order. They accept their preferred offer among all the offers still available in the market.
} 
balance between environmental complexity and the instruments available to investors.

\section{Self-selection of entrepreneurs}

We begin by examining the self-selection process. To simplify the exposition, we begin with the case where there exists exactly one price in each market. At the end of the section we briefly explain the intuition with multiple prices, relegating the formal analysis to the appendix.

Lemma 1. Consider entrepreneurs choosing between a debt contract at $D$ and an equity contract at E. For a given $\sigma$ there exists $\mu^{*}(D, E)$ so that all types with $\mu>\mu^{*}$ prefer debt and all types with $\mu<\mu^{*}$ prefer equity. For a given $\mu$ there exists $\sigma^{*}(D, E)$ so that all types with $\sigma>\sigma^{*}$ prefer debt and all types with $\sigma<\sigma^{*}$ prefer equity.

The intuition of Lemma 1 is that better entrepreneurs (higher expected returns) are attracted to debt, because the entrepreneur does not need to share residual returns. More risky entrepreneurs are attracted to debt because debt creates convex returns for entrepreneurs.

Suppose that only debt is offered at some $D$. Fig. 1a shows that higher $\mu$ and higher $\sigma$ types will apply. The locus of all types that are on their reservation expected utility - we call this the 'marginal debt locus' (MD $\equiv\{\theta \mid$ $U(D, \theta)=K\})$ - is downward sloping. If only equity is offered at some $E$, Fig. $1 \mathrm{~b}$ shows that higher $\mu$ types will apply, irrespective of their $\sigma$. The 'marginal equity locus' $(\mathrm{ME} \equiv\{\theta \mid U(E, \theta)=K\})$ is horizontal. If both debt and equity are offered at $D$ and $E$, Fig. 1c shows what types are attracted to debt and/or equity. Area $A_{2}$ are the types that prefer equity over debt; Area $A_{3}$ are the types that prefer debt over equity; Area $A_{1}$ are the types that would take only equity but not debt; Area $A_{4}$ are the types that would take only debt but not equity; Area $A_{5}$ are the types that do not want to invest at all at the given prices. We call the locus that separates $A_{2}$ from $A_{3}$ the 'switch locus' ( $\left.\mathrm{SW} \equiv\{\theta \mid U(D, \theta)=U(E, \theta) \geq K\}\right)$.

Consider now the possibility of rationing. Denote the probability of being rationed in the debt and equity market by $p_{D}$ and $p_{E}$, respectively. Within a market, rationing is equally likely for any interested entrepreneur. If $\left(1-p_{E}\right)$ is the probability for an entrepreneur in $A_{1}$ to receive equity, then it is also the probability for an entrepreneur in $A_{2}$ to receive equity. This is because

\footnotetext{
${ }^{9}$ The switch locus originates at the point where the MD intersect the ME. This follows from the fact that at this point entrepreneurs are not only indifferent between participating or not, but they are also indifferent between debt and equity.
} 


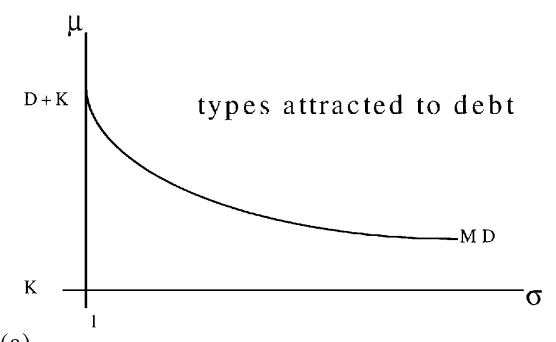

(a)
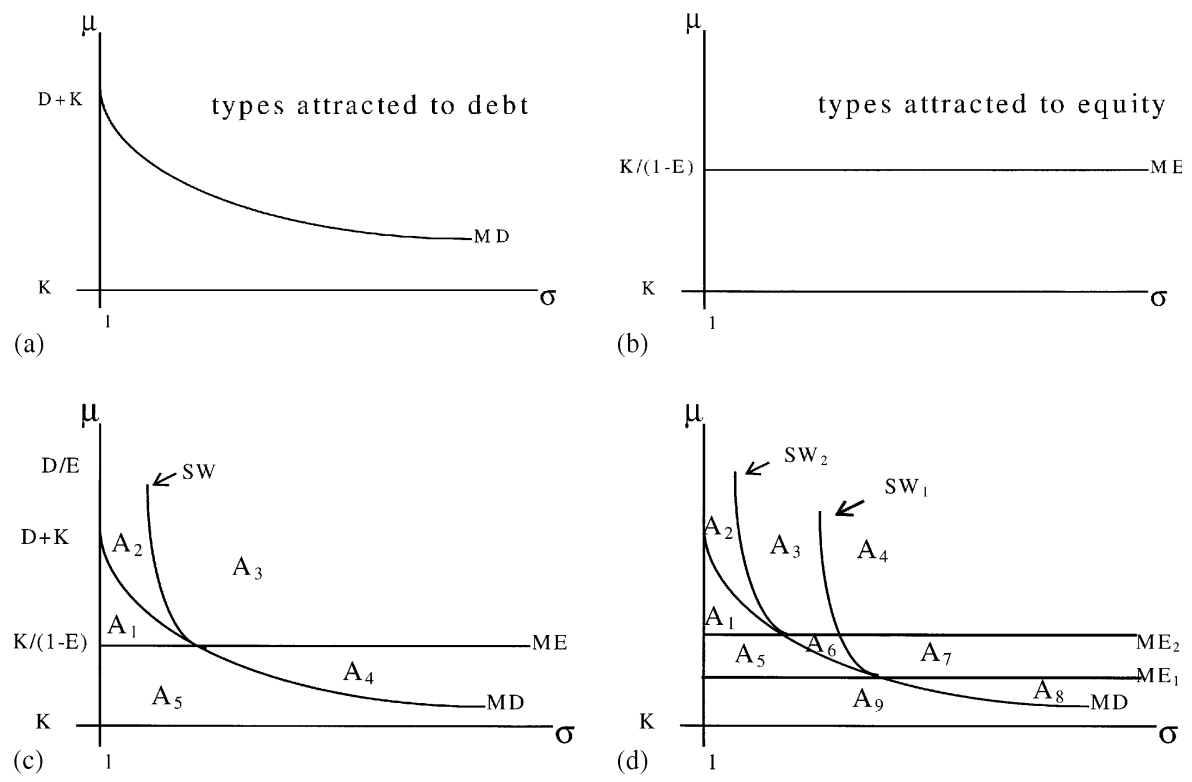

Fig. 1.

entrepreneurs in $A_{1}$ and $A_{2}$ both prefer equity over debt. Similarly, $\left(1-p_{D}\right)$ is the probability for entrepreneurs in $A_{3}$ and $A_{4}$ to receive debt. But entrepreneurs in $A_{2}$ would also accept debt when rationed out of the equity market. The probability that they will accept a debt offer is thus $p_{E}\left(1-p_{D}\right)$. Similarly, the probability that entrepreneurs in $A_{3}$ will accept equity is $p_{D}\left(1-p_{E}\right)$.

In this model, investors first set their quantities $Q_{D}$ and $Q_{E}$, then they set their prices $D$ and $E$. Denote the mass of entrepreneurs in an area $A_{h}$ by $N\left(A_{h}\right)$, $h=1,2,3,4$, where $N\left(A_{h}\right)$ is a function of $(D, E)$. For a given $\left(Q_{D}, Q_{E}, D, E\right)$, $p_{D}$ and $p_{E}$ are thus determined by the equations

$$
\begin{aligned}
& \left(1-p_{E}\right)\left[N\left(A_{1}\right)+N\left(A_{2}\right)+p_{D} N\left(A_{3}\right)\right]=Q_{E}, \\
& \left(1-p_{D}\right)\left[N\left(A_{3}\right)+N\left(A_{4}\right)+p_{E} N\left(A_{2}\right)\right]=Q_{D} .
\end{aligned}
$$

Consider next the case where there are multiple prices in one market. To explain the main intuition, suppose that there is a unique price $D$ in the credit market, but there are two prices, $E_{1}$ and $E_{2}$ with $E_{1}<E_{2}$, in the equity market. While all the entrepreneurs prefer $E_{1}$ over $E_{2}$, their relative preferences over the four options, namely $D, E_{1}, E_{2}$ and $\emptyset$ (for non-participation), may differ. From Fig. 1d we can identify nine relevant areas. Using $\succ$ as a preference ordering, we 
have $A_{1}=\left\{\theta \mid E_{1} \succ E_{2} \succ \emptyset\right\}, \quad A_{2}=\left\{\theta \mid E_{1} \succ E_{2} \succ D \succ \emptyset\right\}, \quad A_{3}=\left\{\theta \mid E_{1} \succ D \succ\right.$ $\left.E_{2} \succ \emptyset\right\}, \quad A_{4}=\left\{\theta \mid D>E_{1} \succ E_{2} \succ \emptyset\right\}, \quad A_{5}=\left\{\theta \mid E_{1} \succ \emptyset\right\}, \quad A_{6}=\left\{\theta \mid E_{1} \succ D \succ \emptyset\right\}$, $A_{7}=\left\{\theta \mid D \succ E_{1} \succ \emptyset\right\}, A_{8}=\{\theta \mid D \succ \emptyset\}, A_{9}=\{\theta \mid \emptyset$ most preferred $\}$. In other words, a type in area $A_{3}$, for example, would choose $E_{1}$ if available; if $E_{1}$ is not available, it would choose $D$ if available; if neither $E_{1}$ nor $D$ available, it would choose $E_{2}$ if available. The demand for funds at any one price thus depends on the number of types that want this contract as their first preference, as well as the number of types that are rationed out of their preferred contracts. From these preference orderings, we can find the rationing probabilities equating supply and demand as follows:

$$
\begin{aligned}
& \left(1-p_{D}\right)\left[p_{E_{1}} p_{E_{2}} N\left(A_{2}\right)+p_{E_{1}} N\left(A_{3}\right)+N\left(A_{4}\right)+p_{E_{1}} N\left(A_{6}\right)\right. \\
& \left.\quad+N\left(A_{7}\right)+N\left(A_{8}\right)\right]=Q_{D}, \\
& \left(1-p_{E_{1}}\right)\left[N\left(A_{1}\right)+N\left(A_{2}\right)+N\left(A_{3}\right)+p_{D} N\left(A_{4}\right)+N\left(A_{5}\right)\right. \\
& \left.\quad+N(A 6)+p_{D} N\left(A_{7}\right)\right]=Q_{E_{1}}, \\
& \left(1-p_{E_{2}}\right) p_{E_{1}}\left[N\left(A_{1}\right)+N\left(A_{2}\right)+p_{D} N\left(A_{3}\right)+p_{D} N\left(A_{4}\right)\right]=Q_{E_{2}} .
\end{aligned}
$$

In the appendix we explain how to generalize this self-selection process to the case with multiple prices in both markets.

\section{Properties of the investors' return functions}

As in the previous section, we relegate the analysis with multiple prices in a market to the end of the section and the appendix, and focus first on the case with a single price per market. The expected returns per project (or equivalently per unit of capital) for debt and equity investors are given by

$$
\begin{aligned}
& R_{D}\left(D, E, p_{D}, p_{E}\right)=\frac{p_{E} V\left(D ; A_{2}\right)+V\left(D ; A_{3}\right)+V\left(D ; A_{4}\right)}{p_{E} N\left(A_{2}\right)+N\left(A_{3}\right)+N\left(A_{4}\right)}, \\
& R_{E}\left(D, E, p_{D}, p_{E}\right)=\frac{p_{D} V\left(E ; A_{3}\right)+V\left(E ; A_{2}\right)+V\left(E ; A_{4}\right)}{p_{D} N\left(A_{3}\right)+N\left(A_{2}\right)+N\left(A_{1}\right)},
\end{aligned}
$$

where $V\left(i ; A_{h}\right) \equiv \int_{\theta \in A_{h}} V(i ; \theta) \mathrm{d} N(\theta), i=D, E$, is a function of $(D, E)$, directly and through $A_{h}$. Investors get different expected returns on different types of entrepreneurs. We define the 'average debt locus' $\left(A D \equiv \theta \mid V(D ; \theta)=R_{D}\right)$ and the 'average equity locus' $\left(A E \equiv \theta \mid V(E ; \theta)=R_{E}\right)$ as the sets of types $\theta$ that yield just average expected returns to their investors. See Fig. 2a and Fig. 2b. For all types to the left (right) of $\mathrm{AD}$, debt investors make higher (lower) than average returns. Similar, for all types above (below) AE, equity investors make higher (lower) than average returns. 


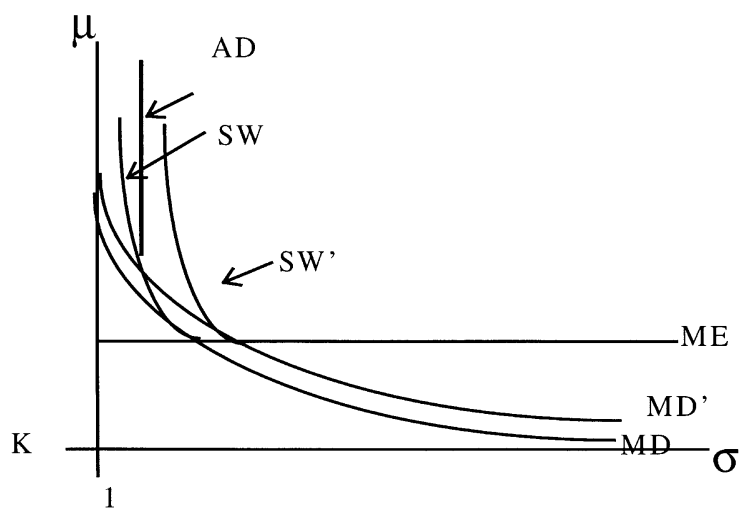

(a)

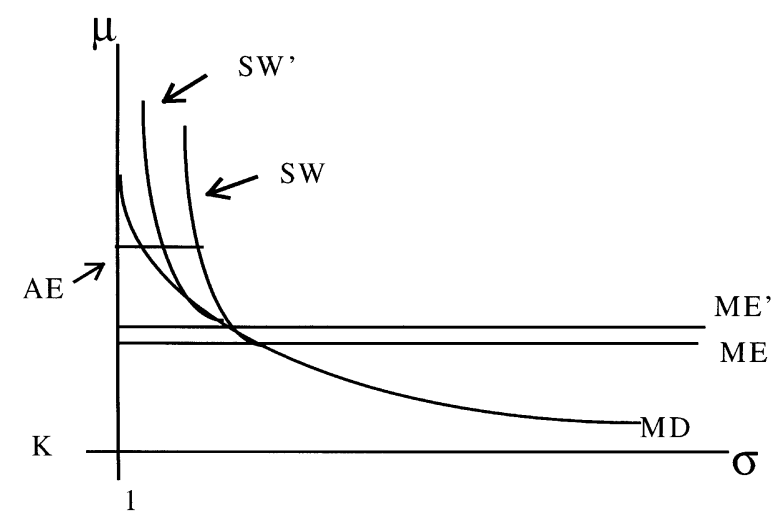

(b)

Fig. 2.

Consider a change in the price of debt, holding everything else constant. ${ }^{10}$ There are two effects. First, taking the pool constant, an increase in the price of debt will increase investor's returns. We call this the price effect, which is always positive. Second, there are changes in the pool of entrepreneurs that self-select into debt. We will now develop a simple graphical argument to examine this selection effect more closely. ${ }^{11}$

\footnotetext{
${ }^{10}$ Technically speaking, we are interested in the partial derivative of $R_{D}$ w.r.t. $D$, holding $E, p_{D}$ and $p_{E}$ constant.

${ }^{11}$ Analytically, the price effect comes from how $D$ changes $V\left(D, A_{h}\right), h=2,3,4$, in $R_{D}$ directly. The selection effect comes from how $D$ changes $A_{h}$ which in turn changes $V\left(D, A_{h}\right)$ and $N\left(A_{h}\right)$.
} 
Fig. 2a considers a small increase in $D$, holding $E, p_{D}$ and $p_{E}$ constant. All entrepreneurs on MD and below ME will leave the debt pool. And entrepreneurs on SW now prefer equity over debt; $\left(1-p_{E}\right) \%$ of them will obtain equity and thus also leave the debt pool. Suppose that AD intersects SW as in Fig. 2a. For debt investors, all types on SW to the left of AD are more profitable than average; all types on SW to the right of $\mathrm{AD}$, as well as all types on MD, are less profitable than average. ${ }^{12}$ This creates an ambiguous effect on $R_{D}$. Losing types that are less profitable than average increases $R_{D}$. This is a positive selection effect. But losing types that are more profitable than average reduces $R_{D}$. This is the adverse selection effect. If the adverse selection effect is sufficiently strong to dominate both the price and the positive selection effect, then $R_{D}$ may be a decreasing function of its own price $D$.

A similar argument holds true for the equity return function. Fig. $2 \mathrm{~b}$ considers a small increase in $E$, holding $D, p_{D}$ and $p_{E}$ constant. All entrepreneurs on ME left of MD will leave the pool. And entrepreneurs on the SW now prefer debt over equity; $\left(1-p_{D}\right) \%$ of them will obtain debt and thus leave the pool for equity. For equity investors, all types on SW above AE are more profitable than average; all types on $\mathrm{SW}$ below $\mathrm{AE}$, as well as all types on ME are less profitable than average. Again, this creates an ambiguous effect on $R_{E}$. Losing types that are less profitable than average increases $R_{E}$ : the positive selection effect. But losing types that are more profitable than average reduces $R_{E}$ : the adverse selection effect. Again, if the adverse selection effect is sufficiently strong to dominate both the price and the positive selection effect, then $R_{E}$ may be a decreasing function of its own price $E$.

We summarize the main insight of this section as follows:

Result 1. If there is asymmetric information about both $\mu$ and $\sigma$, and if there are two types of investors specializing in debt and equity respectively, the return functions to debt and equity investors may be decreasing their own prices.

Result 1 should be contrasted with the results of DeMeza and Webb (1987), which we reconfirm in the appendix. We state them as follows.

Contrast to Result 1. Suppose there are two types of investors specializing in debt and equity, respectively. If there is asymmetric information only about $\mu$, then returns to debt are monotonic in $D$ and they dominate returns to equity. If there is asymmetric information only about $\sigma$, then returns to equity are monotonic in $E$ and they dominate returns to debt.

${ }^{12}$ If AD intersects MD in Area 4, then all types on MD to the left of AD and all types on SW are more profitable than average, and all types on $\mathrm{MD}$ to the right of $\mathrm{AD}$ are less profitable than average. 
DeMeza and Webb used this argument to argue that rationing was unlikely in this model. Result 1 suggests that their analysis depended critically on using a single dimension of asymmetric information. A two-dimensional analysis re-introduces the possibility of non-monotonic return functions. In the next section we will also see that returns in one market may be smaller or larger than returns in the other market.

The analysis with more than one price in a market is a straightforward extension. Again, using the example of a single price in the credit market and two prices in the equity market, the returns to the three contracts $D, E_{1}$ and $E_{2}$ are directly derived from their respective demand:

$$
\begin{aligned}
& R_{D}=\frac{V\left(D ; A_{4} \cup A_{7} \cup A_{8}\right)+p_{E_{1}} V\left(D ; A_{3} \cup A_{6}\right)+p_{E_{1}} p_{E_{2}} V\left(D ; A_{2}\right)}{N\left(A_{4} \cup A_{7} \cup A_{8}\right)+p_{E_{1}} N\left(A_{3} \cup A_{6}\right)+p_{E_{1}} p_{E_{2}} N\left(A_{2}\right)}, \\
& R_{E_{1}}=\frac{\left(E_{1} ; A_{1} \cup A_{2} \cup A_{3} \cup A_{5} \cup A_{6}\right)+p_{D} V\left(E_{1} ; A_{4} \cup A_{7}\right.}{N\left(A_{1} \cup A_{2} \cup A_{3} \cup A_{5} \cup A_{6}\right)+p_{D} N\left(A_{4} \cup A_{7}\right.}, \\
& R_{E_{2}}=\frac{V\left(E_{2} ; A_{1} \cup A_{2}\right)+p_{D} V\left(E_{2} ; A_{3} \cup A_{4}\right)}{N\left(A_{1} \cup A_{2}\right)+p_{D} N\left(A_{3} \cup A_{4}\right)} .
\end{aligned}
$$

The interesting thing to note is that the returns $R_{E_{1}}$ do not depend on $E_{2}$ or $p_{E_{2}}$. Intuitively, the returns to the lower price do not depend on what is happening at the higher price, since all entrepreneurs prefer the lower over the higher price. Furthermore, notice that $R_{E_{2}}$ does not depend on $E_{1}$. This is because the areas $A_{1}, A_{2}, A_{3}, A_{4}$ are defined independent of $E_{2}$ (see Fig. 1d). The intuition is that, while there is a demand for $E_{2}$ by entrepreneurs that are rationed at $E_{1}$, this set of entrepreneurs is drawn from a distribution of rationed entrepreneurs who - since rationing is random - is the same distribution as the one of entrepreneurs who would apply to $E_{2}$ in the absence of $E_{1}$. Finally, $R_{E_{1}}$ does not depend on $p_{E_{1}}$ or $p_{E_{2}}$, i.e., the returns are not affected by the probability of rationing in their own market. Similar for $R_{E_{2}}{ }^{13}$ Together, these observations imply that $R_{E}$ is only a function of $D$ and $p_{D}$. In the appendix we generalize this to say that the returns in one market only depend on the own price and the prices and rationing probabilities in the other market, but not on the other prices in the same market nor the rationing probabilities in the same market. We may thus write a single return function for each market, i.e., $R_{E}\left(E ; D, p_{D}\right)$ and $R_{D}\left(D ; E_{1}, p_{E_{1}}, E_{2}, p_{E_{2}}\right)$.

The reason why these return functions may then be decreasing in their own price is analogous to the previous argument. For any increase in the own price,

\footnotetext{
${ }^{13}$ Obviously, if $p_{E_{1}}=0$, then there is no demand at $E_{2}$. In the appendix we discuss how to take account of this.
} 
there will be a positive price effect, a positive selection effect, and an adverse selection effect; the net effect may go either way.

\section{Equilibrium rationing}

As in Stiglitz and Weiss (1981), the result that the investors' return functions may be decreasing in their own prices is at the heart of rationing. Stiglitz and Weiss emphasized that there is a possibility of rationing, but that its occurrence depends on parameters. In particular, rationing depends on the distribution of types (which affects the shape of the investor's return function) and the quantity of fund supplied (which determines the position on the investor's return function).

Ideally, one would like to have a general characterization of how these model parameters translate into the existence of rationing equilibria. This turns out to be analytically not tractable. But in order to establish the more modest claim that it is possible that there is credit and/or equity rationing in equilibrium, we only need to provide examples. In the appendix we develop a series of fully parameterized, numerical examples to show the existence of the various types of rationing equilibria. To simplify our calculations, we use a sparse density function that has a piecewise linear positive density along one vertical and one horizontal ray, and is zero everywhere else (see Fig. 3a). ${ }^{14}$ In the appendix we discuss the details of the numerical examples.

To convey how we construct a rationing equilibrium, consider the case of rationing in the equity market with market clearing in the debt market. First we choose some $D^{*}$ as the price in the debt market and we set $p_{D}=0$. In the example of the appendix this corresponds to $D^{*}=20$. Using an appropriate density function we generate an equity return function that has a local maximum at $E_{1}^{*}$. Above $E_{1}^{*}, R_{E}$ is decreasing and then increasing again; at $E_{2}^{*}$, $R_{E}$ regains its value, i.e., $R_{E}\left(E_{1}^{*}\right)=R_{E}\left(E_{2}^{*}\right) \equiv R_{E}^{*}$. In the example of the appendix this corresponds to $E_{1}^{*}=0.5, E_{2}^{*}=0.5642$ and $R_{E}\left(E_{1}^{*}\right)=R_{E}\left(E_{2}^{*}\right)=16.47$. See also Fig. 4 d. Denote the demand for funds by $N_{E}\left(E_{1}^{*}\right)$ and $N_{E}\left(E_{2}^{*}\right)$ respectively (given $D^{*}$ and $p_{D}=0$ which we omit in the notation). Choose a total supply of $Q_{E}^{*}$ such that $N_{E}\left(E_{2}^{*}\right)<Q_{E}^{*}<N_{E}\left(E_{1}^{*}\right)$. In the example of the appendix this corresponds to $Q_{E}^{*}=27.35, N_{E}\left(E_{1}^{*}\right)=29.00$ and $N_{E}\left(E_{2}^{*}\right)=12.50$. Since $\left.R_{E}\left(E_{1}^{*}\right)=R_{E}\left(E_{2}^{*}\right)\right)$, equity investors are indifferent between allocating their funds between $E_{1}^{*}$ and $E_{2}^{*}$. Let $\xi$ be the fraction of funds allocated to $E_{1}^{*}$, and let $p_{E}$ be

\footnotetext{
${ }^{14}$ Note that the purpose of these calculations is not to provide a set of elegant simulations, but only to prove the theoretical existence of equilibria with credit and/or equity rationing. Alternatively one may also view the sparse specification as a strength: using only these two rays we are able to generate the full variety of credit and/or equity rationing equilibria.
} 


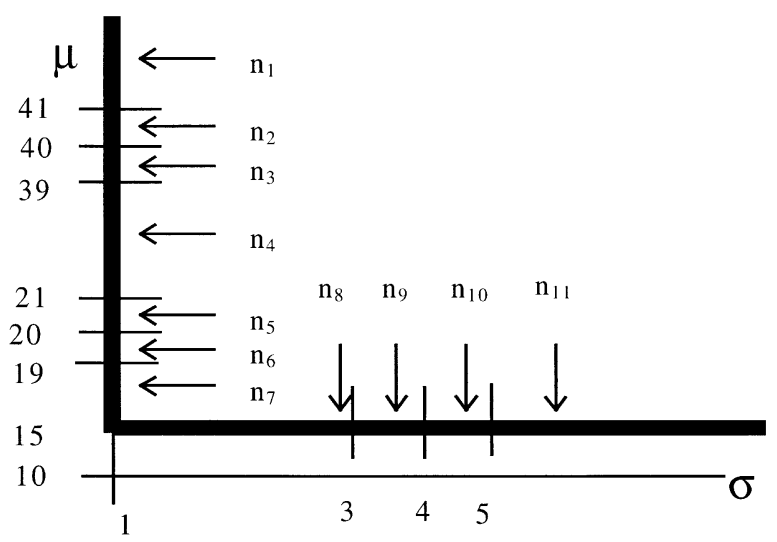

(a)

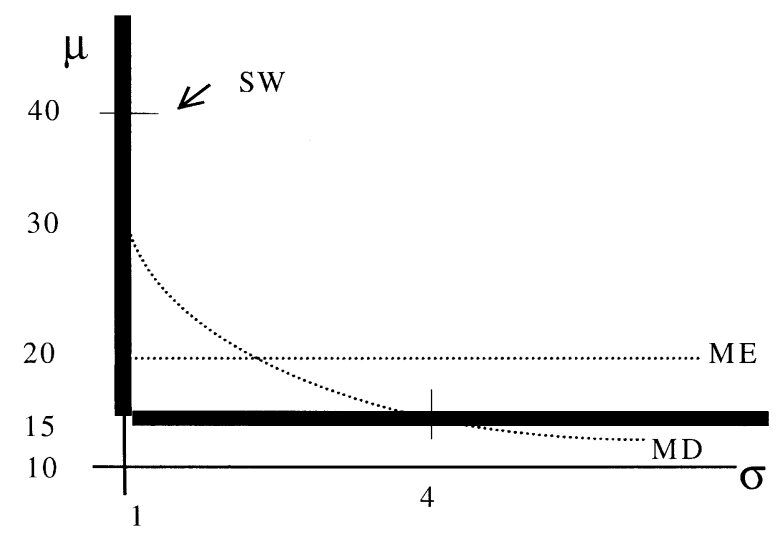

(b)

Fig. 3.

the rationing probability at $E_{1}^{*}$. The equity market is in equilibrium where there is excess demand at $E_{1}^{*}$ but market clearing at $E_{2}^{*} .{ }^{15}$ The equilibrium condition is given by $\left(1-p_{E}\right) N_{E}\left(E_{1}^{*}\right)=\xi Q_{E}^{*}$ and $p_{E} N_{E}\left(E_{2}^{*}\right)=(1-\xi) Q_{E}^{*}$. There is rationing at the low price $E_{1}^{*}$, but all entrepreneurs that are rationed at the low price $E_{1}^{*}$, yet willing to accept the higher price $E_{2}^{*}$ (there are precisely $p_{E} N_{E}\left(E_{2}^{*}\right)$ such

\footnotetext{
${ }^{15}$ The market must clear at the higher price, or else there exists a feasible deviation of offering a price higher than $E_{2}^{*}$ that entrepreneurs who are rationed at $E_{2}^{*}$ would accept. The rationing at the lower price persists because there does not exist another price that would yield a higher return to investors and would be accepted by some entrepreneurs. See also Stiglitz and Weiss (1981).
} 


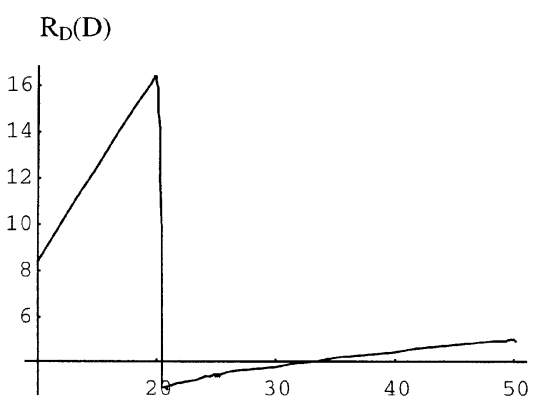

(a)

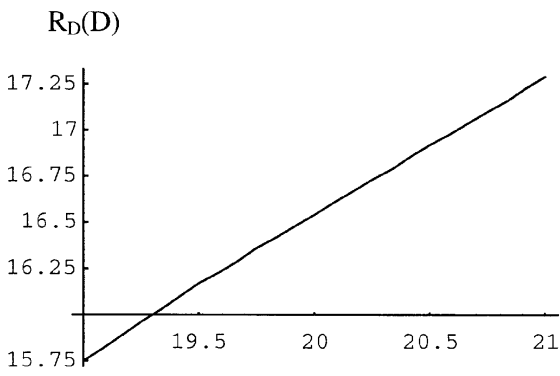

(c)

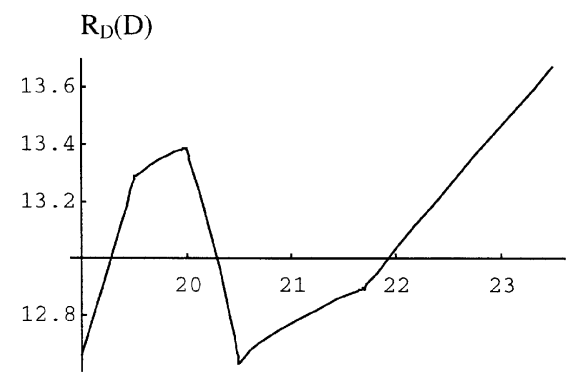

(e)

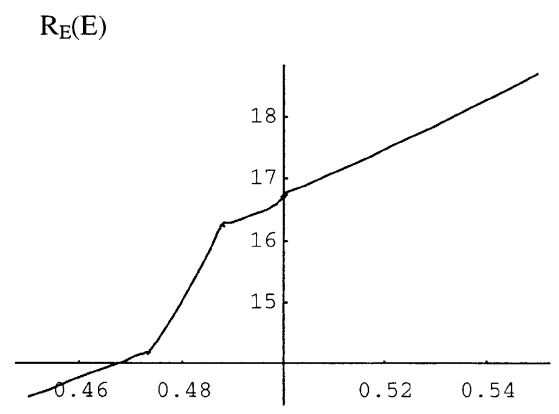

(b)

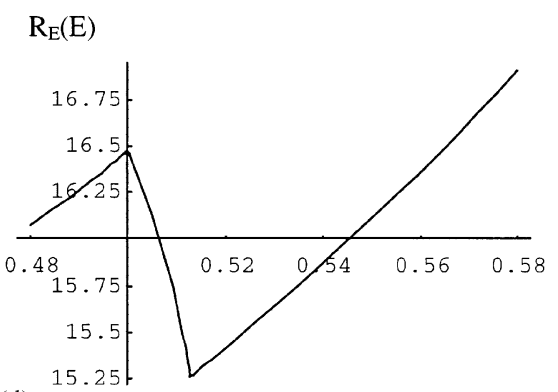

(d)

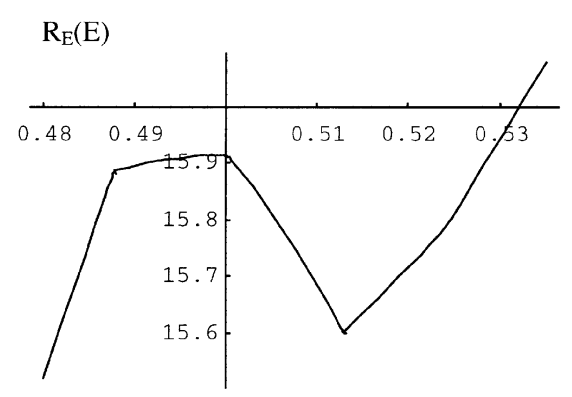

(f)

Fig. 4.

entrepreneurs) all receive funding. In the example of the appendix we have $p_{E}=0.1$, since $(1-0.1) 29+0.112 .5=27.35$. To finish the construction of the equilibrium we choose any supply function that satisfies $Q_{E}\left(R_{E}^{*}\right)=Q_{E}^{*}$. Finally, we need to verify that $R_{D}\left(D^{*} ; E_{1}^{*}, p_{E}^{*}, E_{2}^{*}\right)\left(=R_{D}^{*}\right)$ is non-decreasing at $D^{*}$, and we need to choose any supply function that satisfies $Q_{D}\left(R_{D}^{*}\right)=N_{D}\left(D^{*}\right)$. In the example of the appendix this corresponds to $Q_{D}\left(R_{D}\left(D^{*}\right)\right)=Q_{D}(16.54)=$ 752.36. $R_{D}(D)$ is depicted in Fig. 4 a. 
In the appendix we use this logic to construct other rationing equilibria. Using different parameter values for the density function, we construct an equilibrium with rationing only in the credit market. An interesting difference to the above construction is that the return function has a global interior maximum (see Fig. 4a). This implies that there is only a single price in the market where rationing occurs. ${ }^{16}$ Finally, we also construct an equilibrium with rationing in both the credit and the equity market. From these constructions we can state the main result.

Result 2. If there is asymmetric information about both $\mu$ and $\sigma$, and if there are two types of investors specializing in debt and equity respectively, then it is possible that there is credit rationing, equity rationing or both.

Our examples establish the possibility of the various types of rationing equilibria. This is in line with the previous literature that always emphasized that adverse selection may cause rationing. There typically exist some parameter ranges where the adverse selection effect is not particularly powerful and as a result no rationing occur. But for other parameter ranges the adverse selection effect is sufficiently strong to generate rationing. Our result establishes the equivalent result in the more general setting where there are two markets, credit and equity, and where investors are faced with two-dimensional asymmetric information.

A natural question in our model is whether there can be multiple equilibria. Indeed, the model can generate multiple equilibria, and multiplicity of equilibria is intimately linked to the shape of the supply functions. In the appendix we generate some supply functions such that, in the example of credit and equity rationing, there exists a second equilibrium that contains more rationing in the equity market and less rationing in the credit market. We can also find some supply functions such that the second equilibrium has market clearing in both markets. On the other hand, we also show that it is easy to identify conditions that allow us to rule out the existence of a second equilibrium with both markets clearing. The general point is that, while there may be multiple equilibria in this model, some and possibly all equilibria may feature rationing.

It is also worth mentioning the meaning of rationing in these equilibria. In a two-price equilibrium, those entrepreneurs who are willing to accept the higher price are rationed in the sense that they cannot obtain funds at the same price as other observationally identical entrepreneurs. Those entrepreneurs who are not willing to accept the higher price fail to receive funding in this market. Some of them may seek funding in the other market. If there is rationing in the

\footnotetext{
${ }^{16}$ This is not necessarily the case with credit rationing, as it is straightforward to construct examples with two-price rationing equilibria in the credit market
} 
other market too, they may fail to obtain any funding. Even if there is no rationing some of them may not find any acceptable offer in the other market, and again they are left without funding. ${ }^{17}$ The point is that while an outside observer may look at this environment and argue that there are many opportunities for the entrepreneur to obtain funding, it may well be that the funding that is still available comes at unacceptable terms, and the funding that has acceptable terms is rationed.

Our construction of examples also conveys a strong intuition about the causes of rationing. In general, adverse selection causes rationing when a price increase leads a disproportionately larger number of good types to exit the market. In this model, many of best types are also choosing between debt and equity, and their switching behavior may cause rationing. Intuitively, rationing thus occurs when there are enough good firms switching between these two markets.

To illustrate this further, consider Fig. 3b. In order to create rationing, all our examples allocate a high density around the SW point (at $\mu=40$ and $\sigma=1$ ), i.e., around the point where entrepreneurs switch between the debt and the equity market. This switching behavior causes adverse selection, which induces investors not to raise their prices. In the example with simultaneous credit and equity rationing this adverse selection is strong for both the debt and the equity market. For the construction of the examples with rationing in only one market, the adverse selection effect is strong only in one market (the one that features rationing), but there is some counter-balancing positive selection effect in the other market. ${ }^{18}$

The fact that the density around the switch locus SW is a key driver in all these rationing equilibria suggests that competition between the debt and the equity market may cause rationing. To make this point more precise, consider the following result, which we prove in the appendix:

Contrast to Result 2. If there is asymmetric information about both $\mu$ and $\sigma$, and if all investors specialize only in equity, there cannot be any rationing. If they specialize only in debt, however, there may still be rationing.

The intuition for the first part of the result is that if only equity is offered in the market, then there are no adverse selection effects. This can be seen from the fact

\footnotetext{
${ }^{17}$ For example, when there is equity rationing and credit markets clear, it is easy to see from Fig. $3 \mathrm{~b}$ (interpreting the ME line as pertaining to the lower price) that some of the entrepreneurs who are rationed in the equity market (namely those slightly above $\mu=20$ ) are also not willing to accept debt. They will thus remain without funding.

${ }^{18}$ For example, with equity rationing but credit market clearing there is a high density around the point $\mu=15$ and $\sigma=4$, where the MD intersects the horizontal density ray. This means that investors in the credit market get a strong positive selection effect if they raise their prices, as they will loose a significant number of high-risk, low-return entrepreneurs. This implies that the debt return function is upward sloping and no rationing occurs in the debt market.
} 
that in this case the only selection effects occur along ME, which always lies below AE. The second part is due to Hillier and Ibrahimo (1992), and it is straightforward to construct examples that confirm their result.

This result shows that heterogeneity among investors matters. If investors were all offering equity then the market would always clear. But in such a world, investors specializing in debt would see a profitable opportunity to attract some of the best (high- $\mu$ and low- $\sigma$ ) entrepreneurs away from the equity market. This creates competition between investors in the debt and equity market. If there are many good entrepreneurs who are likely to switch between the two markets, competition to attract them may induce investors in one or both markets to offer prices that are below the Walrasian level, and rationing ensues. Note, however, that if the credit market is our benchmark, competition between the two markets may also reduce rationing. Indeed, we constructed an example where there is credit rationing in the absence of an equity market, but both markets clear after the introduction of an equity market.

\section{Conclusion}

In this paper we ask whether previously disparate theories of credit and equity rationing can be made compatible. We consider a setting where investors specialize either in debt or equity financing, and compete for a common set of entrepreneurs. There is asymmetric information about both the expected returns and the risk of the entrepreneur's projects. We show that there may be credit and/or equity rationing. Moreover, competition between markets may cause rationing. ${ }^{19}$

This paper makes some strong simplifying assumptions. Investors can only offer simple debt and equity contracts, but any combinations of the two, or other more general contracts; and entrepreneurs have no means of signalling their types. We make these assumptions in order to capture an environment that is characterized by a large amount asymmetric information relative to the instruments available to sort out that information. In future research it would be interesting to introduce a wider variety of contracts, especially if one can model them in an environment that is still characterized by a large amount of asymmetric information.

\section{Acknowledgements}

The views expressed in this paper are solely those of the authors and do not necessarily represent those of any organisation with which they are or have been

\footnotetext{
${ }^{19}$ In Hellmann and Stiglitz (1995) we discuss several other extensions of the model and we also derive some additional welfare results.
} 
affiliated. We would like to thank David Starrett, Andrew Weiss and seminar participants at Boston University and the University of Frankfurt for helpful comments. We would also like to thank the Lynde and Harry Bradley Foundation, the M. Olin Foundation and the Sloan Foundation for their financial support.

\section{Appendix}

Proof of Lemma 1. Take $(D, E)$ as given. We have $U(D ; \theta)-U(E ; \theta)=$ $\mu-D / \sigma-(1-E) \mu=E \mu-D / \sigma$. This is an increasing function of $\mu$ and $\sigma$.

Self-selection and rationing probabilities with multiple prices in one market: the extension to the case of multiple prices in one market involves additional notation. Let $\nabla D \equiv\left\{D_{j}\right\}, j=1, \ldots, J_{D}$, and $\nabla E \equiv\left\{E_{j}\right\}, j=1, \ldots, J_{E}$, be the offered price vectors and $\nabla Q_{D} \equiv\left\{Q_{j}\right\}$ and $\nabla Q_{E} \equiv\left\{Q_{j}\right\}$ the associated quantities of funds. For every $\theta$, we can establish a preference ordering over all elements of $\{\nabla D, \nabla E\}$ and the option not to invest, denoted by $\emptyset$. All entrepreneurs will prefer lower prices to higher prices in any one market. Different orderings arise because different types may have different rankings for the different prices across markets and the option not to invest. We can identify $H$ different groups of types that we call $A_{h}, h=1, \ldots, H$, so that all types within a set $A_{h}$ have the same preference ordering over the elements of $\{\nabla D, \nabla E, \emptyset\}$. For every $h$ and $D_{j}$ there then exist a distinct subset of $\{\nabla D, \nabla E\}$ that is the set of prices that all types in $h$ prefer over $D_{j}$. We denote this by $S_{h}\left(D_{j}\right)$. We define the function $P_{h}\left(D_{j}\right)$ as follows: If all types in $A_{h}$ prefer not to invest over accepting $D_{j}$, we have $P_{h}\left(D_{j}\right)$ $=0$; but if all types in $A_{h}$ prefer to accept $D_{j}$ over not investing, we have $P_{h}\left(D_{j}\right)=\left(1-p_{D j}\right) \prod_{p_{i} \in B T_{h}\left(D_{j}\right)} p_{i j}, i=D, E . P_{h}\left(D_{j}\right)$ is the probability for an entrepreneur in $A_{h}$ to accept the offer $D_{j}$. Given $\left\{\nabla D, \nabla E, \nabla Q_{D}, \nabla Q_{E}\right\}$, the following set of equations determines the rationing probabilities $\nabla p_{D} \equiv\left\{p_{D j}\right\}$ and $\nabla p_{E} \equiv\left\{p_{E j}\right\}::^{20}$

$$
\sum_{h=1}^{H} P_{h}\left(D_{j}\right) N\left(A_{h}\right)=Q_{D j}
$$

and

$$
\sum_{h=1}^{H} P_{h}\left(E_{j}\right) N\left(A_{h}\right)=Q_{E j} .
$$

\footnotetext{
${ }^{20}$ Note that if there is excess supply at any of the prices, some $p_{i j}$ might take on a negative value, indicating disequilibrium.
} 
Investor return functions with multiple prices in one market: The investors' return functions are given by

$$
\begin{aligned}
& R_{D j}\left(\nabla D, \nabla E, \nabla_{p D}, \nabla_{p E}\right)=\frac{\sum_{h=1}^{H} P_{h}(D j) V\left(D j ; A_{h}\right)}{\sum_{h=1}^{H} P_{h}(D j) N\left(A_{h}\right)}, \\
& R_{E j}\left(\nabla D, \nabla E, \nabla P_{D}, \nabla P_{E}\right)=\frac{\sum_{h=1}^{H} P_{h}\left(E_{j} V\left(E_{j} ; A_{h}\right)\right.}{\sum_{h=1}^{H} P_{h}\left(E_{j}\right) N\left(A_{h}\right)} .
\end{aligned}
$$

We can identify some irrelevant arguments in the return functions. Consider the set of all types that are willing to accept $D_{j}$. Suppose now that a lower price $D_{k}$ is offered in the debt market. All types that are willing to invest at $D_{j}$ are also willing to invest at $D_{k}$. Suppose that there is some positive rationing probability at this lower price, i.e., $p_{D_{k}}>0$. Since not all entrepreneurs can obtain funds at the lower price, there is still demand for $D_{j}$. The set of types that are now willing to accept $D_{j}$ is reduced by a factor $\left(1-p_{D_{k}}\right)$. But since rationing affects all entrepreneurs equally, it contains the same composition of entrepreneurs. The return per entrepreneur $R_{D_{j}}$ is thus not affected by the lower price. If there is no rationing at $D_{k}$, i.e., $p_{D_{k}}=0$, the denominator of $R_{D_{j}}$ is zero. We can redefine $R_{D_{j}}$ at $p_{D_{k}}=0$ as the (constant) limit of $R_{D_{j}}$ as $p_{D_{k}} \rightarrow 0$. This definition allows us to conclude that $R_{D_{j}}$ is not affected by any lower debt prices. In finding the equilibrium we will obviously use the fact that if there is no rationing at a lower price there is no demand at the higher price.

Consider now a price $D_{l}$ that is higher than $D_{j}$. Since all entrepreneurs prefer $D_{j}$ over $D_{l}$, the selection of types accepting $D_{j}$ is not affected. It follows that $R_{D_{j}}$ is independent of all higher prices for debt. We have thus shown that, holding all $p$ 's and $Q$ 's constant, the $R_{D_{j}}$ function does not depend on any other prices offered in the debt market. We write $R_{D_{j}}=R_{D}\left(D, \nabla E, \nabla p_{E}, \nabla p_{D}\right)$ for $D_{j}$ 's. Using the same reasoning we also have $R_{E_{j}}=R_{E}\left(E, \nabla D, \nabla p_{D}, \nabla p_{E}\right){ }^{21}$ Since individual debt investors are small, they take $\left\{\nabla E, \nabla p_{E}, \nabla p_{D}\right\}$ as given. It follows that we can use $R_{D}\left(D, \nabla E, \nabla p_{E}, \nabla p_{D}\right)$ to evaluate the returns to individual debt investors offering a price different from a proposed equilibrium price.

\footnotetext{
${ }^{21}$ In fact, $R_{D_{j}}$ does not depend on $\nabla p_{D}$ either: If entrepreneurs accept a contract $D_{j}$, they must have been rejected at all cheaper debt prices. $R_{D_{j}}$ thus contains all terms $P_{D_{k}}$ with $D_{k}<D_{j}$ in both the numerator and denominator. These terms cancel out, i.e., $R_{D_{j}}$ is independent of them. Similarly for $P_{D_{j}}$ itself. And since all entrepreneurs prefer $D_{j}$ over any $D_{l}$ with $D_{l}>D_{j}$, the rationing probabilities $p_{D_{l}}$ are also irrelevant to $D_{j}$. It follows that $R_{D_{j}}$ is independent of $\nabla p_{D}$. Similarly, $R_{E}$ is independent of $\nabla p_{E}$.
} 
Proof of the contrast to Result 1 . If $\mu$ is the only parameter of asymmetric information, then $R_{D}=D / \sigma$, which is independent of $\mu . R_{D}$ is monotonic in $D$ since there is only the positive price effect and there are no selection effects. Suppose now that for $(D, E)$ both debt and equity investors attract a positive mass of entrepreneurs and let $\mu_{S W}$ be the switch point. For all $\mu<\mu_{S W}$ we have $U(E, \mu)=(1-E) \mu>\mu-D / \sigma=U(D, \mu)$. This implies $E \mu<D / \sigma$, but $V(E, \mu)=$ $E \mu$ and $V(D, \mu)=D / \sigma$, so that $V(E, \mu)<V(D, \mu)$ for all types that prefer equity. It follows that $R_{E}<R_{D}$.

If $\sigma$ is the only parameter of asymmetric information, then $R_{E}=E \mu$, which is independent of $\sigma . R_{E}$ is monotonic in $E$. Suppose now that for $(D, E)$ both debt and equity investors attract a positive mass of entrepreneurs and let $\sigma_{S W}$ be there switch point. For all $\sigma>\sigma_{S W}$ we have $U(E, \mu)=(1-E) \mu<\mu-D / \sigma=U(D, \mu)$, so that $E \mu<D / \sigma$, so that $V(E, \mu)>V(D, \mu)$ for all types that prefer debt. It follows that $R_{D}<R_{E}$.

Discussion of numerical examples. We will now explain how we constructed the main numerical examples. A full description of all the variations of these examples, as well as the Mathematica programs used in the calculations are available from the authors upon request.

We choose a sparse density function: $n(\mu, \sigma)$ is zero everywhere, except for two line segments. The first line segment is vertical at $\sigma=1$ and extends from $\mu=15$ to $\mu=100$; the second line segment is horizontal at $\mu=15$ and extends from $\sigma=1$ to $\sigma=10$. The points $\left\{\mu=m_{j}, \sigma=1\right\}$ with $m_{j}$ given by $m_{0}=100$, $m_{1}=41, m_{2}=40, m_{3}=39, m_{4}=21, m_{5}=20, m_{6}=19, m_{7}=15$ subdivide the vertical line into seven regions. And the points $\left\{\mu=15, \sigma=m_{j}\right\}$ with $m_{j}$ given by $m_{8}=3, m_{9}=4, m_{10}=5, m_{11}=10$ subdivide the horizontal line into four regions. We use a piecewise constant density for these regions and denote the density by $n_{1}-n_{11}$ as shown in Fig. 3a. For all examples we assume that the entrepreneur's opportunity costs are given by $K=10$.

We choose this simple density function because it considerably simplifies the numerical calculations. The piecewise constant density function creates kinked return functions, but our results do not depend on this kink. ${ }^{22}$ Again, the purpose of these calculations is not to provide an elegant simulation, but merely to establish the theoretical possibility of rationing equilibria.

\footnotetext{
${ }^{22}$ All that matters for the equilibria is that the return functions are decreasing in their own price over some range (see Section 3). Note also that the continuity properties of the model directly imply that any smooth approximation to our density function would yield the same equilibrium within an $\varepsilon$-approximation. Such smooth approximations would also not have to be restricted to density functions that have positive density only along two line segments.
} 
Credit Rationing. Consider the following values for the density:

\begin{tabular}{lllllllllll}
\hline$n_{1}$ & $n_{2}$ & $n_{3}$ & $n_{4}$ & $n_{5}$ & $n_{6}$ & $n_{7}$ & $n_{8}$ & $n_{9}$ & $n_{10}$ & $n_{11}$ \\
\hline 0 & 100 & 1 & 1 & 1 & 100 & 1 & 1 & 1 & 1 & 5 \\
\hline
\end{tabular}

Suppose that $E=50 \%$, then Fig. 4 a shows $R_{D}(D) . R_{D}$ reaches a global maximum at $D=20$. This creates the possibility for credit rationing. At $D=20$ and $E=50 \%$ returns to debt are $R_{D}=16.46$ and the demand for funds is $N_{D}=126$. If we want to construct an equilibrium with $10 \%$ rationing, we can choose any supply function that satisfies $Q_{D}\left(R_{D}=16.46\right)=0.9 \times 126=113.4$. If debt investors want to offer only 113.4 units of fund,there is excess demand for funds. Entrepreneurs have a 10\% probability of not receiving any debt.

From Fig. 4a we immediately see that debt investor would not want to offer a higher price than $D=20$. We also need to verify that equity investors indeed want to offer $E=50 \%$. Fig. $4 \mathrm{~b}$ reveals that for $D=20$ and $p_{D}=0.1, R_{E}$ is an increasing function of $E$. At $E=50 \%$ we have $R_{E}=16.75$ and $N_{E}=30$, so that any supply function satisfying $Q_{E}\left(R_{E}=16.75\right)=30$ closes the equilibrium.

It is worth noting that the rationing result does not depend on one market achieving higher returns than the other. In the example above $R_{D}=16.46<16.75=R_{E}$. By changing the density $n_{11}$, for example, we can make the returns to debt equal or higher than the returns to equity. At $n_{11}=4.4746$, for example, $R_{D}=16.75=R_{E}$, and at $n_{11}=4, R_{D}=17.02$ $>16.75=R_{E}$. In all these cases the rationing outcome is maintained. An equivalent observation can also be made for all the other examples below.

Equity rationing. Consider the following values for the density:

\begin{tabular}{lllllllllll}
\hline$n_{1}$ & $n_{2}$ & $n_{3}$ & $n_{4}$ & $n_{5}$ & $n_{6}$ & $n_{7}$ & $n_{8}$ & $n_{9}$ & $n_{10}$ & $n_{11}$ \\
\hline 10 & 10 & 10 & 1 & 1 & 10 & 1 & 1 & 1 & 1 & 30 \\
\hline
\end{tabular}

For $D=20$, Fig. 4 d shows $R_{E}(E) . R_{E}$ has a local maximum at $E_{1}=50 \%$, but this is not a global maximum. Stiglitz and Weiss (1981) first showed that in such circumstances the equilibrium entails two prices. ${ }^{23}$ To construct the two-price

\footnotetext{
${ }^{23}$ Suppose $E_{1}=50 \%$ was the only price and there was rationing. In this case an equity investor would find it profitable to offer equity at a higher price. From Fig. $4 \mathrm{~d}$ we see that a price $E=58 \%$, for example, would yield higher profits. And because there is rationing at the lower price, some entrepreneurs will accept the higher price.
} 
equilibrium, suppose that 26.10 units of funds are being offered at $E_{1}=50 \%$. With a demand $N_{E}\left(E_{1}=50 \%\right)=29.00$, there is a $10 \%$ probability of rationing. Our calculations show that $R_{E}\left(E_{1}=50 \%\right)=16.47$, and $R_{E}$ regains this value at $E_{2}=56.42 \%$. If $E_{2}=56.42 \%$ was the only price, there would be a demand of $N_{E}\left(E_{2}=56.42 \%\right)=12.50$. But since only rationed entrepreneurs will accept the higher price, only $10 \%$ of 12.50 , or 1.25 is the effective demand. With any supply function that satisfies $Q_{E}\left(R_{E}=16.47\right)=26.10+1.25=27.35$, investors can allocate 26.10 to $E_{1}=50 \%$ and 1.25 to $E_{2}=56.42 \%$, given that they are indifferent between $E_{1}$ and $E_{2}$. Now there is no rationing at $E_{2}=56.42 \%$ so that no investor can offer a higher price. But from Fig. $4 \mathrm{~d}$ all other prices yield a lower return. It follows that $E_{1}=50 \%$ and $E_{2}=56.42 \%$ are equilibrium prices. Again, we also need to verify that debt investors indeed want to offer $D=20$. Fig. $4 \mathrm{c}$ reveals that for $E_{1}=50 \%, E_{2}=56.42 \%$ and $p_{E_{1}}=0.1, R_{D}$ is an increasing function of $D$. At $D=20$ we have $R_{D}=16.54$ and $N_{D}=752.36$, so that any supply function satisfying $Q_{D}\left(R_{D}=16.54\right)=752.36$ closes the equilibrium.

Credit and equity rationing. Consider the following values for the density:

\begin{tabular}{lllllllllll}
\hline$n_{1}$ & $n_{2}$ & $n_{3}$ & $n_{4}$ & $n_{5}$ & $n_{6}$ & $n_{7}$ & $n_{8}$ & $n_{9}$ & $n_{10}$ & $n_{11}$ \\
\hline 1 & 20 & 20 & 5 & 1 & 10 & 1 & 1 & 100 & 1 & 10 \\
\hline
\end{tabular}

The equilibrium prices are given by $D_{1}=20, D_{2}=22.81, E_{1}=50 \%$ and $E_{2}=52.89 \%$. Fig. $4 \mathrm{e}$ and Fig. $4 \mathrm{f}$ shows $R_{D}(D)$ and $R_{E}(E)$, taking the equilibrium prices in the other market as given. At the equilibrium prices we have $R_{D}=13.385$ and $R_{E}=15.915$. The (single price) demands are given by $N_{D}\left(D_{1}=20\right)=132.593, N_{D}\left(D_{2}=22.81\right)=105.067, N_{E}\left(E_{1}=50 \%\right)=113.462$, $N_{E}\left(E_{2}=52.89 \%\right)=87.743$. Suppose the supply of funds at $D_{1}$ is $0.91 \times$ $32.593=119.334$ and at $E_{1}$ it is $0.9 \times 113.462=102.116$, then there is a $10 \%$ rationing probability in both markets. If the supply of funds at $D_{2}$ is $0.1 \times$ $105.067=10.507$ and at $E_{2}$ it is $0.1 \times 87.743=8.774$, then there is no rationing at these two prices. It follows that any supply functions satisfying $Q_{D}\left(R_{D}=13.385\right)=$ $119.334+10.507=129.841$ and $Q_{E}\left(R_{E}=15.915\right)=102.116+8.774=110.890$ close the equilibrium.

Discussion of multiple equilibria, using the example of credit and equity rationing. We also constructed a second equilibrium for this case with the following values: $p_{D}=0.095, p_{E}=0.105, D_{1}=20, D_{2}=22.83, E_{1}=0.5$, $E_{2}=52.93 \%, R_{D}=13.398, R_{E}=15.910, N_{D}\left(D_{1}\right)=132.737, N_{D}\left(D_{2}\right)=105.044$, $N_{E}\left(E_{1}\right)=113.342, N_{E}\left(E_{2}\right)=87.288$. This is an equilibrium if our supply functions $Q_{D}\left(R_{D}\right)$ and $Q_{E}\left(R_{E}\right)$ not only satisfy $Q_{D}\left(R_{D}=13.385\right)=129.841$ and $Q_{E}\left(R_{E}=15.915\right)=110.890$, but also satisfy $Q_{D}\left(R_{D}=13.398\right)=130.106$ and $Q_{E}\left(R_{E}=15.910\right)=110.607$. 
We can use yet another set of supply functions to generate a second equilibrium with both markets clearing. Use $p_{D}=0 ; p_{E}=0, D=19.5, E=0.525$, then $R_{D}=13.589, R_{E}=15.276, N_{D}(D)=169.286, N_{E}(E)=80.451$. We can therefore obtain a second equilibrium by choosing any supply functions that satisfy $Q_{D}\left(R_{D}=13.385\right)=129.841$ and $Q_{D}\left(R_{D}=13.589\right)=169.286$, and $Q_{E}\left(R_{E}=\right.$ $15.915)=110.890$ and $Q_{E}\left(R_{E}=15.276\right)=80.451$.

To generate these multiple equilibria, we impose specific restrictions on the supply functions. We can also take the opposite approach and look for restrictions on the supply function that eliminates certain kinds of equilibria. In particular, we may be interested in finding restrictions, such that there does not exist any equilibrium with both markets clearing. To do this in our example, suppose that apart from the rationing equilibrium (denoted by *) there existed another pair of prices $\left(D^{\prime}, E^{\prime}\right)$ such that both markets clear. Suppose that $R_{D}^{\prime} \equiv R_{D}\left(D^{\prime}, E^{\prime}\right)>R_{D}^{*}$, then we can choose a supply function $Q_{D}\left(R_{D}\right)$, such that $Q_{D}\left(R_{D}^{\prime}\right)>N_{D}\left(D^{\prime}, E^{\prime}\right)$. Similarly, if $R_{D}^{\prime}<R_{D}^{*}$, then $Q_{D}\left(R_{D}^{\prime}\right)<N_{D}\left(D^{\prime}, E^{\prime}\right)$. By assuming a sufficiently elastic supply of fund we can eliminate all equilibria with a different return than $R_{D}^{*}$. Similar for $R_{E}^{*}$. We thus only need to verify that there does not exist another equilibrium with $R_{D}^{\prime}=R_{D}^{*}=13.385$ and $R_{E}^{\prime}=R_{E}^{*}=15.915$. For this we generate the Walrasian prices $\left(D^{\prime}, E^{\prime}\right)$ that satisfy $N_{D}\left(D^{\prime}, E^{\prime}\right)=Q_{D}\left(R_{D}^{\prime}\right)=Q_{D}\left(R_{D}^{*}\right)=129.841$ and $N_{E}\left(D^{\prime}, E^{\prime}\right)=Q_{E}\left(R_{E}^{\prime}\right)=Q_{E}\left(R_{E}^{*}\right)=110.890$. These are given by $D=20.024$ and $E=0.5060$. Straightforward inspection reveals then that at these prices both return function are strictly decreasing in their own prices. This implies that for these parameter values there cannot exist another equilibrium without rationing.

Intuition for the rationing outcome in the numerical examples. Consider Fig. 3b. In all our examples $D=20$ and $E=50 \%$ are the (lowest) equilibrium prices in the two markets. ME is given by the point $\{\mu=20, \sigma=1\}, \mathrm{MD}$ is given by the points $\{\mu=30, \sigma=1\}$ and $\{\mu=15, \sigma=4\}$ and $\mathrm{SW}$ is given by the point $\{\mu=40, \sigma=1\}$. The key intuition in the credit rationing example is that the high density $n_{2}$ implies that raising the price above $D=20$ is not profitable for debt investors since a large portion of profitable entrepreneurs would switch to the equity market. The high density at $n_{6}$ insures that the equity return function does not have a local maximum at $E=50 \%$. In the equity rationing example the high density $n_{3}$ relative to $n_{4}$ and $n_{5}$ (where all other entrepreneurs that accept equity are located) implies that equity investors do not want to raise their prices above $50 \%$ so as not to lose the relatively profitable entrepreneurs around SW. Returns to debt remain monotone at $D=20$ since the density $n_{4}$ is low compared to $n_{1}, n_{2}$ and $n_{3}$. In the credit and equity rationing example, finally, both $n_{2}$ and $n_{3}$ have a high density, implying that neither debt nor equity investors have an incentive to raise their prices. The high densities at $n_{6}$ and $n_{9}$ ensure that investors do not want to lower their prices either. 
Proof of the contrast to Result 2. If there is no debt market, then the returns to equity are given by $R_{E}=E \int_{\mu_{0}}^{\infty} \mu \mathrm{d} N(\mu) / \int_{\mu_{0}}^{\infty} \mathrm{d} N(\mu)$ where $\mu_{0}=K /(1-E)$. This is an increasing function of $E$. There is no adverse selection effect in this case and thus there cannot be any rationing.

\section{References}

Bester, H., 1985a. The level of investment in credit markets with imperfect information. Journal of Institutional and Theoretical Economics 141, 503-515.

Bester, H., 1985b. Screening versus rationing in credit markets with imperfect information. American Economic Review 75 (4), 850-855.

Brennan, M., Kraus, A., 1987. Efficiency financing under asymmetric information. Journal of Finance 42, 1225-1243.

Cho, Y., 1986. Inefficiencies from financial liberalization in the absence of well-functioning equity markets. Journal of Money, Credit, and Banking 18 (2), 191-199.

DeMeza, D., Webb, D., 1987. Too much investment: A problem of asymmetric information Quarterly Journal of Economics May 102 (2), 281-292.

Greenwald, B., Stiglitz, J., Weiss, A., 1984. Informational imperfections in the capital markets and macro-economic fluctuations. American Economic Review 74 (1), 194-199.

Grinblatt, M., Hwang, C.Y., 1989. Signaling and the pricing of new issues. Journal of Finance 46 (2), 393-420.

Hellmann, T., Stiglitz, J., 1995. A unifying theory of credit and equity rationing in markets with adverse selection. Working paper \# 1356, Graduate School of Business, Stanford University.

Hillier, B., Ibrahimo, M.V., 1992. The performance of credit markets under asymmetric information about project means and variances. Journal of Economic Studies 19 (3), 3-17.

Leland, H., Pyle, D., 1977. Informational asymmetries, financial structure, and financial intermediation. Journal of Finance 32, 371-387.

Milde, H., Riley, J., 1988. Signaling in credit markets. Quarterly Journal of Economics 103 (1), 101-129

Myers, S., Majluf, N., 1984. Corporate financing and investment decisions when firms have information that investors do not have. Journal of Financial Economics 13, 187-221.

Stiglitz, J., 1982. Information and capital markets. Reprint 339, National Bureau of Economic Research, Cambridge, MA.

Stiglitz, J., Weiss, A., 1981. Credit rationing in markets with imperfect information. American Economic Review 71 (3), 393-410.

Stiglitz, J., Weiss, A., 1986. Credit rationing and collateral. In: Edwards, J., Franks, J., Mayer, C., Schaefer, S. (Eds.), Recent Developments in Corporate Finance. Cambridge University Press, Cambridge.

Stiglitz, J., Weiss, A., 1987. Macro-economic equilibrium and credit rationing. Working paper 2164, National Bureau of Economic Research, Cambridge, MA.

Stiglitz, J., Weiss, A., 1990. Sorting out the differences between screening and signaling models. Technical working paper no. 93, National Bureau of Economic Research, Cambridge, MA.

Wette, H., 1983. Collateral in credit rationing in markets with imperfect information: Note. American Economic Review 73 (3), 442-445.

Williamson, S., 1987. Costly monitoring, loan contracts, and equilibrium credit rationing. Quarterly Journal of Economics, February, 135-145. 